\title{
PUEBLOS INDÍGENAS Y DERECHOS: UNA DISCUSIÓN A LA LUZ DE LAS POLÍTICAS PÚBLICAS DESDE EL CASO CHILENO
}

Verónica Figueroa Huencho 


\section{VERÓNICA FIGUEROA HUENCHO}

Es Doctora en Ciencias dela Gestión por ESADE (España). Realizó sus estudios de postdoctorado en el Centro de Estudios Latinoamericanos de la Universidad de Stanford (EE.UU) en el área de políticas públicas indígenas. Profesora Asociada del Instituto de Asuntos Públicos (INAP) de la Universidad de Chile. Ha sido Directora de la Escuela de Gobierno y Gestión Pública de la Universidad de Chile y se ha desempeñado como consultora para el Forum Universal de la Culturas (Barcelona), el Banco Interamericano de Desarrollo y la Organización de Estados Iberoamericanos para la Educación, la Ciencia y la Cultura, entre otros. Sus líneas de investigación principal son las políticas públicas indígenas y la gestión pública intercultural. Tiene publicaciones en esa materia que consisten en libros y capítulos de libros en editoriales nacionales e internacionales, y artículos en revistas académicas especializadas. 


\section{PUEBLOS INDÍGENAS Y DERECHOS: UNA DISCUSIÓN A LA LUZ DE LAS POLÍTICAS PÚBLICAS DESDE EL CASO CHILENO}

\section{INTRODUCCIÓN}

Desde la creación de los Estados-nación, los pueblos indígenas se han visto obligados a adoptar formas de vida ajena a sus culturas, a sus cosmovisiones, debiendo asumir comportamientos considerados aceptables por una sociedad occidental que ha marcado la pauta de su desarrollo, compuesta por quienes han ocupado espacios de poder político o económico, y que han utilizado dichos espacios para imponer no sólo sus modelos de vida sino también para ejercer su potestad de definir la estructura institucional y valórica a la que deben ajustarse todos aquellos individuos que habiten dentro de sus límites estatales.

Sin embargo, aun cuando han pasado siglos desde la conformación de estos Estados, los pueblos indígenas todavía deben experimentar la exclusión producto de la colonización no sólo de sus espacios territoriales, sino también en sus modos de relación, de pensamiento o de organización, viéndose obligados a acomodar sus formas de vida a las impuestas por la sociedad occidental. Es así como se han visto despojados de sus tierras, han sido explotados como mano de obra y han visto debilitadas sus instituciones ancestrales, entre otros. En términos generales, la comparación entre población indígena y no indígena demuestra que la pobreza, la desnutrición, las enfermedades, la emigración, la desorganización social, entre otros, son considerablemente mayores en los pueblos indígenas, asociados asimismo a la pérdida progresiva de su patrimonio lingüístico, medicinal y cultural, por mencionar algunos (Figueroa, 2017).

Esta discriminación histórica los ha mantenido en roles secundarios en la toma de decisiones, reforzando la lógica colonial basada en la negación de la existencia de los pueblos indígenas como verdaderos actores en la toma de decisiones, especialmente de aquellas situaciones que les afectan, por lo que terminan siendo vistos como miembros de culturas que deben ser superadas en pos de avanzar hacia una mayor modernidad (Walsh, 2006). En ese sentido, parte del problema que enfrentan los pueblos indígenas es que a pesar de la incorporación de la diversidad como aspiración en diferentes instancias políticas, "los proyectos estatales aún están atrapados en viejos conceptos, donde no existe real voluntad política no sólo para reconocer la multiculturalidad sino para arbitrar las medidas pertinentes en términos de que esta tenga posibilidades reales de desarrollo" (Walsh, 2000:8). 
Es por ello que en las últimas décadas la comunidad internacional ha debido generar instancias específicas de protección a los derechos de los pueblos indígenas, especialmente aquellos vinculados a los derechos humanos, políticos, sociales, culturales y económicos, para favorecer la generación de cuerpos normativos y legales en los distintos Estados que consideren la diversidad actual, pero también la adecuación de sistemas de representación que den real cabida al ejercicio legítimo de estos derechos. Este rol activo, sin embargo, ha sido forzado por una serie de movilizaciones y reivindicaciones que los pueblos indígenas han impulsado con fuerza, dando mayor notoriedad a demandas culturales, territoriales, económicas y/o políticas, lo que ha dado cuenta de las limitaciones de los enfoques de derechos y la escasa voluntad de algunos gobiernos por respetarlos.

En el caso chileno, al igual que en la mayoría de los Estados latinoamericanos, aún persisten situaciones que vulneran el ejercicio adecuado de los derechos de los pueblos indígenas. De hecho, la denominada Ley Indígena No 19.253 del año 1993 aparece descontextualizada a la luz de los nuevos desafíos que impone el avance en el reconocimiento de derechos en el ámbito internacional, especialmente al no entregar el estatus de "pueblo" a los indígenas y hablar de "etnias" diferenciadas respecto del resto de la población. Se requiere, por tanto, identificar aquellas dimensiones que podrían favorecer un cambio real en la representación e implementación de los derechos de los pueblos indígenas, de su participación en todos aquellos ámbitos que los afectan, considerando los estándares internacionales en esta materia, tal como el Convenio 169 de la OIT o los diferentes pactos que nuestro país ha suscrito, como el Pacto Internacional de Derechos Económicos, Sociales y Culturales y el Pacto Internacional de Derechos Civiles y Políticos.

De esa forma, la discusión en torno al reconocimiento de derechos desde diferentes instancias internacionales y las decisiones de los gobiernos a través de las políticas públicas nacionales (expresadas en leyes u otros instrumentos) deben ser analizadas en conjunto, de manera de identificar las posibles disociaciones pero, sobre todo, las brechas que aún persisten en estas materias, definiendo así una hoja de ruta que guíe la toma de decisiones a la luz de los desafíos actuales. Esto nos lleva a repensar y reformular una serie de aspectos vinculados al proceso de formulación de políticas públicas, pues ya no se trata de un proceso neutral sino que se reconocen en él la confrontación de intereses y visiones entre actores que disponen de diferentes recursos y mecanismos de acceso a la toma de decisiones, y que muchas veces buscan limitar el ejercicio de los derechos de los pueblos indígenas.

Las políticas reflejan maneras de pensar sobre el mundo y cómo actuar en él, traduciendo modelos implícitos (y algunas veces explícitos) de las sociedades dominantes y de las visiones acerca de cómo los individuos debieran relacionarse 
con la sociedad o los unos con los otros. ¿Estamos, en el caso de Chile, tomando decisiones que respetan el ejercicio de los derechos de estos pueblos? ¿Cuáles son las principales brechas que aún persisten en esta materia? ¿Cuáles son los puntos estratégicos que requieren atención para dar cuenta de una sociedad diversa, justa, con protagonismo de los pueblos indígenas?

En este artículo nos abocaremos a responder algunas de estas preguntas a partir del análisis de las principales disposiciones contenidas en diferentes normas internacionales y su efectiva (o no) aplicación al contexto de los pueblos indígenas en Chile, entregando elementos de juicio que favorezcan un mejor análisis de la realidad que enfrentan estos pueblos. Para ello, en el primer apartado nos referiremos de manera descriptiva a las principales normativas establecidas en el derecho internacional que sirven de marco para la toma de decisiones en políticas nacionales. En el segundo apartado analizaremos diferentes disposiciones contenidas en estas normas a la luz de la realidad de los pueblos indígenas en Chile, evidenciando aspectos que requieren de avances en materia de políticas indígenas. Finalmente, entregaremos un conjunto de conclusiones y reflexiones al respecto.

\section{DESCRIPCIÓN Y ANÁLISIS DE LAS PRINCIPALES NORMATIVAS INTERNACIONALES}

Existen diferentes instrumentos que han sido ratificados por nuestro país que resultan relevantes para favorecer un ejercicio adecuado de derechos de los pueblos indígenas en diferentes materias, pues los derechos humanos suponen dar un pleno goce a diferentes aspectos que impactan en la vida de los pueblos indígenas y en sus reales posibilidades de existencia. Es aquí donde conceptos como "pueblo", "autonomía", "libre determinación”, entre otros, adquieren especial relevancia, pues a la luz de estos instrumentos pueden ser ejercidos por los pueblos indígenas. Sin embargo, también es importante analizar otros aspectos específicos vinculados a los derechos sociales, como salud o educación, o derechos lingüísticos, temas que han estado presentes también en las demandas ejercidas por estos pueblos en las últimas décadas.

Un instrumento internacional de especial relevancia es la Declaración de Derechos de Pueblos Indígenas de la Asamblea General de Naciones Unidas, de reciente aprobación (2007), por cuanto busca relacionar los derechos humanos con los pueblos indígenas en un intento por considerar sus propias realidades y especificidades, siendo un esfuerzo que busca enmendar la exclusión histórica que estos pueblos han tenido en el sistema jurídico internacional (Naciones Unidas, 2013). En esta declaración, que constituye el instrumento más amplio relativo a los 
derechos de los pueblos indígenas existente en el ámbito del derecho y las políticas internacionales, figuran normas mínimas en materia de reconocimiento, protección y promoción de estos, orientando a los Estados y pueblos indígenas en la elaboración de leyes y políticas que les afectan, especialmente en el establecimiento de medios para atender mejor sus reclamaciones.

La declaración aborda, entre otros, los derechos individuales y los derechos colectivos, los derechos culturales y la identidad, y los derechos a la educación, la salud, el empleo y el idioma. El texto afirma que los pueblos indígenas tienen derecho, como pueblo o como personas, al disfrute pleno de todas las libertades fundamentales y los derechos humanos reconocidos por la Carta de las Naciones Unidas, la Declaración Universal de Derechos Humanos y la normativa internacional de los derechos humanos. Asimismo, señala que los pueblos y las personas indígenas son libres e iguales a todos los demás pueblos y personas y tienen derecho a no ser objeto de ninguna discriminación en el ejercicio de sus derechos que esté fundada, en particular, en su origen o identidad indígena. Los pueblos indígenas tienen derecho a la libre determinación y en virtud de este derecho pueden decidir libremente su condición política y perseguir libremente su desarrollo económico, social y cultural.

En otros aspectos, señala que los pueblos indígenas tienen derecho a conservar y reforzar sus propias instituciones políticas, jurídicas, económicas, sociales y culturales, manteniendo a la vez su derecho a participar plenamente, si lo desean, en la vida política, económica, social y cultural del Estado. En materia lingüística, señala que los pueblos indígenas tienen derecho a revitalizar, utilizar, fomentar y transmitir a las generaciones futuras sus historias, idiomas, tradiciones orales, filosofías, sistemas de escritura y literaturas.

Otro instrumento sustantivo para los pueblos indígenas es el Convenio 169 de la OIT, ratificado por Chile en el año $2008^{1}$, que se convierte en un importante avance en materia de reconocimiento de derechos indígenas, especialmente por lo señalado en su artículo 6": "al aplicar las disposiciones del presente Convenio, los gobiernos deberán: a) consultar a los pueblos interesados, mediante procedimientos apropiados y en particular a través de sus instituciones representativas, cada vez que se prevean medidas legislativas o administrativas susceptibles de afectarles directamente; b) establecer los medios a través de los cuales los pueblos interesados puedan participar libremente, por lo menos en la misma medida que otros sectores de la población, y a todos los niveles en la adopción de decisiones en instituciones

1. Cabe recordar que el Convenio 169 ingresó al Congreso en 1991, siendo aprobado con una votación transversal mayoritaria el 11 de abril de 2000 por la Cámara de Diputados. Sin embargo, sería finalmente aprobado por el Senado el 4 de marzo de 2008 por 36 votos a favor y uno en contra, después de 17 años de trámite parlamentario. 
electivas y organismos administrativos y de otra índole responsables de políticas y programas que les conciernan; c) establecer los medios para el pleno desarrollo de las instituciones e iniciativas de esos pueblos, y en los casos apropiados proporcionar los recursos necesarios para este fin".

Sin embargo, este convenio también resulta sustantivo en otros ámbitos. Por ejemplo, en el ámbito de las lenguas señala que siempre que sea viable, deberá enseñarse a los niños de los pueblos interesados a leer y a escribir en su propia lengua indígena o en la lengua que más comúnmente se hable en el grupo a que pertenezcan. Cuando ello no sea viable, las autoridades competentes deberán celebrar consultas con esos pueblos con miras a la adopción de medidas que permitan alcanzar este objetivo. Para ello los gobiernos deberán adoptar disposiciones para preservar las lenguas indígenas de los pueblos interesados y promover el desarrollo y la práctica de las mismas.

En materia de salud, por ejemplo, también es relevante para los pueblos indígenas por cuanto señala en su artículo $25^{\circ}$ que los gobiernos deberán velar porque se pongan a disposición de los pueblos interesados servicios de salud adecuados o proporcionar a dichos pueblos los medios que les permitan organizar y prestar tales servicios bajo su propia responsabilidad y control, a fin de que puedan gozar del máximo nivel posible de salud física y mental. Asimismo, los servicios de salud deberán organizarse, en la medida de lo posible, a nivel comunitario. Estos servicios deberán planearse y administrarse en cooperación con los pueblos interesados y tener en cuenta sus condiciones económicas, geográficas, sociales y culturales, así como sus métodos de prevención, prácticas curativas y medicamentos tradicionales.

Otro instrumento relevante para los pueblos indígenas es la Declaración Universal sobre los Derechos Lingüísticos (1997), la que establece que estos son derechos humanos individuales y colectivos porque se ejercen en una comunidad. Entre ellos existe una serie de derechos personales inalienables y ejercibles en cualquier situación, tales como el derecho a ser reconocido como miembro de una comunidad lingüística; el derecho al uso de la lengua en privado y en público; el derecho al uso del propio nombre; el derecho a relacionarse y asociarse con otros miembros de la comunidad lingüística de origen; el derecho a mantener y desarrollar la propia cultura; el derecho a la enseñanza de la propia lengua y cultura; el derecho a disponer de servicios culturales; el derecho a una presencia equitativa de la lengua y la cultura del grupo en los medios de comunicación; y el derecho a ser atendidos en su lengua en los organismos oficiales y las relaciones socioeconómicas, entre otros. Además, la declaración reconoce los derechos lingüísticos en los ámbitos de la administración pública y órganos oficiales, la enseñanza, los medios de comunicación y nuevas tecnologías, la cultura y el ámbito socioeconómico. 
Entre otros instrumentos también merecen ser destacados el Pacto Internacional de Derechos Económicos, Sociales y Culturales, el que contiene una serie de derechos tales como la libre determinación, en virtud de la cual los pueblos establecen libremente su condición política y proveen asimismo a su desarrollo económico, social y cultural. Asimismo, señala que para el logro de sus fines, todos los pueblos pueden disponer libremente de sus riquezas y recursos naturales, sin perjuicio de las obligaciones que derivan de la cooperación económica internacional basada en el principio de beneficio recíproco, así como del derecho internacional. En ningún caso podrá privarse a un pueblo de sus propios medios de subsistencia.

En la misma línea se encuentra el Pacto Internacional de Derechos Civiles y Políticos, el que señala que en los Estados en que existan minorías étnicas, religiosas o lingüísticas no se negará a las personas que pertenezcan a dichas minorías el derecho que les corresponde, en común con los demás miembros de su grupo, a tener su propia vida cultural, a profesar y practicar su propia religión y a emplear su propio idioma.

Estas y otras normativas constituyen un marco de referencia sustantivo para la toma de decisiones en el ámbito de las políticas públicas estatales, las que no deben contravenir estas disposiciones sino más bien propender a su pleno ejercicio y goce por parte de los pueblos indígenas. Sin embargo, en el caso de Chile existen algunas brechas importantes que deben ser abordadas de manera urgente para dar cabida al respeto necesario que promueva la generación de confianzas entre los pueblos indígenas y el Estado. En ese sentido, cómo se tomen las decisiones, quiénes lo hagan o desde qué marcos culturales o políticos se definan las políticas no es algo que deba ser dejado al azar. Más bien, deben formar parte de un ejercicio necesario que promueva espacios para que los pueblos indígenas sean realmente actores centrales de su desarrollo.

En el siguiente apartado nos abocaremos a realizar un análisis sobre algunos ámbitos del ejercicio del derecho para el caso de Chile, el que no pretende abordar todas las temáticas y problemas asociados sino más bien dar algunas luces de los sesgos que aún persisten en nuestro marco normativo e institucional.

\section{EL EJERCICIO DE LOS DERECHOS INDÍGENAS EN CHILE: UNA REFLEXIÓN ACTUAL}

Si bien Chile ha ratificado todos los pactos y declaraciones señaladas en el apartado anterior, aún existen brechas en el efectivo ejercicio de algunos acuerdos considerados relevantes por los pueblos indígenas, que van desde aspectos de carácter político hasta los vinculados a los derechos educativos, lingüísticos y territoriales, entre otros. Entre las principales brechas que aún persisten y que requieren cambios en las políticas públicas actuales podemos encontrar las que a continuación se describen. 
En primer lugar, sin duda que la principal de estas brechas se encuentra en la falta de reconocimiento de "pueblos indígenas", como hemos señalado. Como excusa para no abordar este punto en ese momento, el gobierno se amparó en que "la ratificación del Convenio 169 se debía realizar desde el Congreso Nacional, por lo tanto quedaba fuera de la Ley y escapaba a las atribuciones del ejecutivo" (Entrevista a ex asesor, en Figueroa, 2014). De esa manera, la ley reconoce "etnias" diferenciadas cultural y lingüísticamente respecto de la población nacional, pero sin un estatus legal que reconozca sus derechos de pueblo. Sin embargo, el Convenio 169 de la OIT fue ratificado por Chile en el año 2008 y no se han producido cambios en esta materia.

En las discusiones llevadas adelante como parte del proceso constituyente indígena realizadas en el año 2017, uno de los aspectos clave a ser incluidos en la nueva Constitución fue el reconocimiento de pueblos. De hecho, es un tema consignado en prácticamente todas las actas y uno cuya presencia es transversal y constante. Cuando en las actas se alude a este tema se lo vincula con los tratados internacionales vigentes sobre los derechos de los pueblos indígenas (Informe Proceso Constituyente Indígena, 2017). Junto con ello, el reconocimiento de pueblos trae aparejado otros aspectos importantes, entre ellos cómo se entenderán conceptos relevantes como "representatividad, autonomía, participación y consulta". La autonomía también debe ser clarificada no sólo en su alcance sino también en cómo se ejercerá, de acuerdo a criterios territoriales, ancestrales, comunitarios, etc.

En segundo lugar, otro aspecto relevante ha sido el derecho a la consulta que consagra el Convenio 169. En el caso de Chile, más allá del acto político de su ratificación en el año 2009 se ha evidenciado cómo diferentes decisiones desde el propio Poder Ejecutivo han buscado limitar el ejercicio de estos derechos a través de reglamentos específicos que buscan enmarcar los procesos de consulta sin respetar la cosmovisión de estos pueblos o sus propios mecanismos de decisión. Entre ellos, el derogado decreto $\mathrm{N}^{\mathrm{0}} 124$ promulgado el 25 de septiembre de 2009 y que buscaba regular la consulta y la participación de los pueblos indígenas, el que fue criticado por estos pueblos al ser definido de manera arbitraria y unilateral por parte del gobierno, limitando gravemente el derecho de consulta.

Ese mismo año, el propio Instituto Nacional de Derechos Humanos en su informe anual del año $2010^{2}$, señalaba que este decreto no cumplía con las normas internacionales de derechos aplicables a la consulta, recomendando al gobierno y a todos los poderes del Estado que tomen medidas para garantizar el cumplimiento

2. http://bibliotecadigital.indh.cl/bitstream/handle/123456789/41/informe_anual_2010. pdf? sequence $=1$ 
del deber de consulta de acuerdo a los estándares internacionales. Producto de estas críticas, este decreto fue derogado, siendo reemplazado por el decreto $\mathrm{N}^{\circ} 66$ del año 2014, el que regula el procedimiento de consulta indígena en virtud del artículo 6 No1 letra a) y No2 del Convenio 169 de la Organización Internacional del Trabajo sobre Pueblos Indígenas y Tribales en Países Independientes.

Este decreto también ha sido denunciado por los pueblos indígenas no sólo por restringir sus derechos sino porque el propio mecanismo de consulta establecido no respetó los términos establecidos en el Convenio. Efectivamente, el propio Comité de Derechos Económicos, Sociales y Culturales, en julio de 2015, manifestó su preocupación "[...] por la falta de un mecanismo legal que garantice la obtención del consentimiento previo, libre e informado de los pueblos indígenas en relación a la toma de decisiones que pudieran afectar al ejercicio de sus derechos económicos, sociales y culturales", señalando que el Estado de Chile debe tomar "las medidas legislativas y administrativas necesarias para garantizar la obtención del consentimiento previo, libre e informado de los pueblos indígenas en lo que respecta a la toma de decisiones susceptible de afectar directamente el ejercicio de sus derechos económicos, sociales y culturales".

En tercer lugar, varias normativas internacionales hacen mención a la necesidad de contar con una institucionalidad que permita el pleno ejercicio de los derechos de los pueblos indígenas, así como una adecuada representación de sus intereses tanto en las dimensiones políticas como estratégicas. En el caso de Chile, la institución que actualmente gestiona la política indígena (no la define, pues no tiene esas atribuciones) es la Corporación Nacional de Desarrollo Indígena (Conadi)". Esta corporación se definió como un organismo público, descentralizado, con personalidad jurídica y patrimonio propio, dependiente del Ministerio de Planificación y Cooperación (actualmente Ministerio de Desarrollo Social), cuya misión es promover, coordinar y ejecutar la acción del Estado en favor del desarrollo integral de las personas y comunidades indígenas en lo económico, social y cultural, así como impulsar su participación en la vida nacional.

Por lo tanto, como ya se indicaba anteriormente, esta Corporación no representa a los pueblos indígenas sino a la acción del Estado a favor de estos ${ }^{3}$. Con ello, la Conadi no cuenta con atribuciones para definir la política indígena, sino que la ley le asigna el carácter de servicio público con muy pocas atribuciones políticas, entregándole sólo funciones de promoción, coordinación y ejecución de

3. Actualmente se encuentran en trámite parlamentario dos proyectos de ley: uno que crea el Ministerio de Asuntos Indígenas y otro que crea el Consejo Nacional y los Consejos de Pueblos Indígenas. Sin embargo, dado que aún no se han promulgado, rige la institucionalidad creada por la ley 19.253 del año 1993. 
las acciones que los diferentes gobiernos definan a favor de los pueblos indígenas. Con ello se genera una tensión, pues se trata de un organismo que responde a las orientaciones políticas de los gobiernos de turno, dejando en manos de un consejo escasas atribuciones de representación, lo que limita su campo de acción estratégico-político y le deja poco margen de maniobra para solucionar conflictos tan complejos como aquellos vinculados a la compra de tierras.

Efectivamente, la ley asigna a la Conadi la gestión de un aspecto complejo como es la demanda territorial a través de un instrumento denominado Fondo de Tierras y Aguas Indígenas y que en su aspecto central se refiere a la solución de litigios sobre tierras entre personas indígenas, comunidades indígenas y particulares, provenientes de los títulos de merced u otras cesiones o asignaciones hechas por el Estado a favor de los indígenas. Asimismo, el fondo contempla el otorgamiento de un subsidio para la adquisición de tierras por parte de los indígenas. Del mismo modo, la Conadi ejecuta el Fondo de Desarrollo Indígena, que tiene por objetivo permitir el desarrollo productivo de las poblaciones indígenas beneficiadas con las tierras adquiridas a través del Fondo de Tierras y Aguas.

En cuarto lugar, relacionado con lo anterior, también encontramos una limitación al ejercicio de derechos territoriales que reconoce la norma internacional, pues la ley 19.253 sólo reconoce la existencia de tierras. Si bien, amparado en la norma internacional, se han definido demandas por la creación de un territorio (o territorios) para el desarrollo indígena, entendido como un espacio geográfico definido por criterios de relación ancestral donde se pudieran conseguir algunos niveles de autodeterminación o autogestión, como ocurre en otros países como Panamá o Bolivia, se ha optado por favorecer la propiedad individual o comunitaria del terreno y la regularización de su tenencia por parte de las comunidades.

Es así como se habla de "tierras indígenas", cuya propiedad tendrá como titulares a las personas naturales indígenas o a la comunidad indígena definida por la propia ley. Junto con ello se reconoce el rol del Estado de proteger las tierras indígenas, velando por su adecuada explotación, por su equilibrio ecológico y propendiendo a su ampliación. Con ello se da inicio a uno de los puntos en conflicto que permanecerán hasta los gobiernos actuales y que han formado parte de las demandas permanentes de los pueblos indígenas: la restitución del territorio ancestral como sustento de su desarrollo.

Para subsanar aspectos vinculados al territorio, la ley habla del reconocimiento de “áreas de desarrollo indígena”, donde corresponderá al Ministerio de Planificación y Cooperación ${ }^{4}$ (a propuesta de la Conadi) establecer áreas de desarrollo indígena que

4. Actual Ministerio de Desarrollo Social. 
serán "espacios territoriales en que los organismos de la administración del Estado focalizarán su acción en beneficio del desarrollo armónico de los indígenas y sus comunidades", con lo cual el concepto de comunidad no se ve reflejado, rompiendo así un elemento fundamental de la cultura y existencia indígena. Para algunos sectores del Ejecutivo, el elemento cultural ya estaba implícito en la "prohibición de vender tierras a no indígenas", con lo cual ya se estaba respetando su cosmovisión.

Actualmente existen diez Áreas de Desarrollo Indígena: Jiwasa Oraje, localizada en la provincia de Iquique; Alto Andino en la provincia de Arica y Parinacota; Atacama La Grande y Alto El Loa, provincia de El Loa; Te Pito o Tenua en la provincia de Isla de Pascua; Lleu- Lleu en la provincia de Arauco; Alto Biobío en la provincia de Biobío; Lago Budi en la provincia de Cautín; Puel Nahuelbuta en la provincia de Cautín-Malleco; y Cabo de Hornos en la provincia de la Antártica Chilena (Rubilar y Roldan, 2014).

Esta estrategia de desarrollo requiere ser revisada, pues si bien se han generado esfuerzos focalizados, las cifras aún siguen mostrando situaciones complejas en términos de pobreza. Aunque los datos de la encuesta Casen muestran una disminución de la pobreza indígena, esta se mantiene en un 23,4\% frente al 13,5\% que representa la pobreza no indígena. Respecto de la región de La Araucanía, la pobreza asciende a un 18,2\% y en la población mapuche es de $24,34 \%$.

En quinto lugar, la normativa internacional establece la necesidad de respetar las formas de organización y representación de los pueblos indígenas, cuestión que aún permanece sin resolver. Uno de estos aspectos es el propio reconocimiento jurídico de las comunidades, lo que suponía introducir lógicas de estructuración y funcionamiento distintas a las comunidades ancestrales, incorporando elementos propios de la "sociedad wingkea" que a la larga debilitarían redes de relaciones tradicionales (Figueroa, 2014). La ley 19.253 establece que la constitución de las comunidades será acordada "en asamblea que se celebrará con la presencia del correspondiente notario oficial del Registro Civil o Secretario Municipal, donde se aprobarán los estatutos de la organización y se elegirá su directiva, levantando una acta que incluirá la nómina e individualización de los miembros de la Comunidad (mayores de edad) que concurrieron a la Asamblea constitutiva, y de los integrantes de sus respectivos grupos familiares" y agrega que "la Comunidad gozará de personalidad jurídica por el solo hecho de realizar el depósito del acta constitutiva".

En sexto lugar, un aspecto relevante en materia de derechos es la posibilidad de continuar y fortalecer su cosmovisión a través del uso de la lengua y de la generación

5. Wingka es una palabra en mapudungún que se utiliza para referirse al "extraño, al que no es mapuche". Generalmente se usa de forma despectiva. 
de sistemas educativos que nazcan desde su propia cultura. En el caso de Chile, esto quedó reducido al reconocimiento de un "sistema de educación intercultural bilingüe" en las áreas de alta densidad indígena a fin de preparar a los educandos indígenas para desenvolverse en forma adecuada tanto en su sociedad de origen como en la sociedad global. Con ello se debilita otro aspecto importante de las posturas indígenas vinculadas a la lengua, donde la ley define un mandato pero no establece recursos ni define lineamientos claros para ello, pues depende de la discusión anual del presupuesto. Por otra parte, la decisión de este sistema descansa en la voluntad del Ministerio de Educación, aun cuando la experiencia y el conocimiento ancestral se encuentran en las propias comunidades, en sus autoridades tradicionales.

En el año 1996, al alero de la recién creada Conadi, esta institución y el Ministerio de Educación crearon, a través de un convenio de colaboración, el Programa de Educación Intercultural Bilingüe (PEIB), que consideró proyectos piloto en escuelas y liceos con alta matrícula de estudiantes de origen indígena insertos dentro del Programa de Educación Básica Rural. Sus principales objetivos fueron mejorar la calidad de la educación de los estudiantes pertenecientes a pueblos originarios, fortaleciendo su identidad y autoestima; incorporar contenidos didácticos correspondientes a su realidad cultural, social e histórica; e incorporar a las familias y comunidades indígenas en los procesos de definiciones curriculares y métodos de enseñanza aprendizaje.

Como una forma de mejorar los indicadores, el Ministerio de Educación, a través del decreto No280 del 2009, creó el "Sector de Lengua Indígena” (SLI) para todos los establecimientos educativos que deseen incorporar dentro de sus planes y programas de estudio esta asignatura. Ello, porque para el 2009, a más de 13 años de creado el PEIB, las cifras de conocimiento de la lengua no habían logrado mejorar. Datos de la Casen muestran que para ese año más del 70\% de la población infantil y juvenil no hablaba ni entendía su lengua. Desde 2010, aquellos establecimientos con estudiantes entre primero y octavo básico con un 50\% de matrícula de ascendencia indígena y un 20\% desde 2013, han debido implementar la asignatura de Lengua Indígena de manera obligatoria, con el apoyo de los programas de estudio elaborados por la Unidad de Currículum y Evaluación del Ministerio de Educación, una vez aprobados por el CNED.

Sin embargo, la última encuesta Casen 2016 muestra que para el año 2015 sólo un $10,7 \%$ de la población indígena hablaba y entendía su lengua. Un 10,7\% sólo la entendía y un $78,6 \%$ no hablaba ni entendía. Esta última cifra se ha mantenido con escasas variaciones desde el año 2009. Si desagregamos estas cifras por rangos etarios nos encontramos con una realidad más compleja aún, pues es la población infantil y juvenil la que muestran un mayor desconocimiento de su lengua. Efectivamente, un 88,6\% de población indígena de 0 a 14 años declara no 
hablarla ni entenderla, lo mismo que declara la población de 15 a 29 años, con un $82,6 \%$. Esto supone que estamos asistiendo a una pérdida progresiva de la lengua, que queda en conocimiento de la población adulta o adulta-mayor y que de no contar con mecanismos o espacios adecuados para su socialización, corre riesgo de desaparecer. El reconocimiento de derechos lingüísticos para los pueblos indígenas es una materia urgente en nuestro país.

Esta breve revisión en torno a algunos aspectos específicos del ejercicio de derechos en Chile a través de diferentes políticas públicas generadas para ello, da cuenta de las brechas que aún persisten y que debilitan el reconocimiento de las demandas indígenas en materia de los derechos de participación; la insuficiencia de recursos para hacer frente a las necesidades de las comunidades indígenas del país, así como la natural evolución de las demandas y necesidades de los pueblos indígenas que continúan reclamando, amparados en la normativa internacional, el derecho al reconocimiento de pueblos, la protección, el control de las tierras y los recursos naturales, el derecho a participar en la toma de decisiones de los procesos que los afecten y el derecho a mantener y desarrollar la cultura (Rubilar y Roldan, 2014).

De hecho, el informe que surgió de la visita realizada por el relator especial de Naciones Unidas James Anaya en el año 2009 señala que "entre los rezagos más graves se encuentran el que los pueblos indígenas se sienten excluidos de la toma de decisiones de las políticas gubernamentales y legislativas que les conciernen; la inexistencia de un mecanismo en la ley para el reconocimiento de los derechos a la tierra o a las recursos naturales en base a la ocupación ancestral indígena conforme a previas recomendaciones y al derecho internacional sobre la materia; el que las compras de tierras resultan en la fragmentación de los territorios mapuche; y el que no se hayan cumplido las recomendaciones del Relator Especial anterior y las normas del Convenio 169 en relación a los proyectos de explotación de los recursos naturales en tierras y territorios indígenas" (Consejo de Derechos Humanos, 2009).

En concordancia con lo anterior, en su reciente visita de 2015, el relator especial de la ONU sobre extrema pobreza, Philip Alston, también se refirió a algunas situaciones que podrían estar vulnerando el ejercicio de derechos por parte del Estado de Chile, indicando que "los derechos de los pueblos indígenas son el talón de Aquiles del historial de Chile en lo que respecta a los derechos humanos en el siglo XXI. Las cuestiones controvertidas son complejas, diversas y no tienen fácil solución. Sin embargo, no parece haber mayor disposición a hacerles frente salvo de manera superficial. Ahora bien, si el Gobierno se propone seriamente acabar con la extrema pobreza y reducir la desigualdad, la política sobre cuestiones indígenas debe constituir un elemento esencial" (Naciones Unidas, 2016: p.15). En el mismo informe se señala que "la fragmentaria respuesta del Estado chileno a lo 
que se reconoce como un problema de exclusión, marginación y discriminación y su especial renuencia a intervenir para poner remedio a los principales motivos de preocupación han hecho que las políticas chilenas fueran duramente criticadas por toda una serie de órganos internacionales".

Lo anterior da cuenta de la urgencia de contar con marcos jurídicos que consideren no sólo las reclamaciones y demandas de los pueblos indígenas, sino también con mecanismos que permitan evidenciar los intereses y valores que diferentes actores con cuotas de poder han intentado colocar en la agenda de decisiones. De esa forma se estarán generando espacios transparentes para definir, de mejor forma, aquellos aspectos relevantes para los pueblos indígenas, resguardando que sean consideradas sus propias cosmovisiones, tanto en las normas internacionales como en las políticas públicas.

\section{CONCLUSIONES}

Las decisiones de política pública cobran aquí un lugar fundamental para dar cabida real al ejercicio de los derechos consagrados en los instrumentos internacionales. En el caso de Chile existen diferentes estudios e informes que dan cuenta de la necesidad de cambiar el paradigma desde el cual estamos tomando las decisiones en el ámbito del Estado, como una forma de disminuir las inequidades e injusticias a las que se ven enfrentados los pueblos indígenas. Banting y Kymlicka (2006) señalan que en términos de políticas en diversidad, América Latina aún presenta debilidades, principalmente referidas a sus instituciones, la oposición de las élites a la inclusión de derechos constitucionales y la desvaloración que se tiene de los pueblos indígenas, lo que ha significado que en algunos casos estas políticas sólo existen en el papel.

Si bien las declaraciones de Naciones Unidas u otros instrumentos no tienen fuerza jurídica obligatoria, sí representan el cambio y el dinamismo del marco jurídico internacional y buscan reflejar el compromiso de los Estados en avanzar en una cierta dirección y respetar determinados principios. De esa forma, estos instrumentos proporcionan una interpretación de los derechos humanos consagrados en otros instrumentos internacionales de derechos humanos de resonancia universal, específicamente en lo que respecta a su aplicación a los pueblos y personas indígenas. En este sentido, la declaración tiene un efecto vinculante para la promoción, el respeto y el cumplimiento de los derechos de los pueblos indígenas en todo el mundo. Sin embargo, un aspecto importante es recoger de manera adecuada la visión que los propios pueblos indígenas tienen de los elementos que deben ser recogidos en estas declaraciones, para dar cuenta fiel de su cosmovisión. 
Las políticas públicas han jugado (y siguen jugando) un rol central en la construcción de las denominadas "sociedades diversas" y cabrá, por tanto, reconocer este rol en casos específicos. Pero se requiere asumir un debate en torno al tipo de sociedades que se construyen, a las concepciones privilegiadas en torno a ellas, incluso a los puntos de partida desde donde se está incorporando a los pueblos indígenas, quienes si bien son anteriores a la construcción analítica (incluso artificial) de los países o del propio modelo Estado-nación, poseen saberes que han sido subvalorados y marginados desde las lógicas occidentales de construcción social y política.

Muchas iniciativas y estrategias de desarrollo han fallado por no tomar en cuenta la especificidad de los pueblos indígenas en términos sociales, políticos, culturales o económicos, generalizando y asumiendo unas características homogéneas para toda la población. Las políticas públicas han seguido esta tendencia a la importación de propuestas en materia de desarrollo indígena y una débil recreación autóctona de ellas, en el sentido de que no han sido estos pueblos quienes han propuesto las bases de su desarrollo (Rey, 2002).

En definitiva, es necesario continuar avanzando en el reconocimiento de derechos indígenas, pero sin olvidar los necesarios debates que pongan en cuestionamiento los presupuestos que han gobernado el devenir de la política pública latinoamericana por décadas (Rodríguez y Domínguez, 2011). 


\section{REFERENCIAS}

Banting, Keith y Kymlicka, Will (2006). "Introduction: multiculturalism and the welfare state: setting the context", en Banting y Kymlicka (eds), Multiculturalism and the Welfare State: recognition and redistribution in contemporary democracies, Oxford: Oxford University Press.

Consejo de Derechos Humanos (2009). Recomendaciones del relator especial de la ONU sobre derechos indígenas, James Anaya. La situación de los pueblos indígenas en Chile.

Figueroa Huencho, Verónica (2014). Formulación de políticas públicas indígenas en Chile. Santiago: Editorial Universitaria.

Figueroa Huencho, Verónica. (2017). "Institucionalidad pública, participación y representación política de los pueblos indígenas en Chile", en Aninat, I.; Figueroa, V. y González, R. (Eds.) El pueblo mapuche en el siglo XXI: propuestas para un nuevo entendimiento entre culturas en Chile. Santiago de Chile: CEP. Pp. 227-264.

Informe Proceso Constituyente Indígena (2017). Sistematización del proceso participativo constituyente indígena. MIDESO, Santiago de Chile, mayo 2017.

Naciones Unidas (2013). Los pueblos indígenas y el sistema de derechos humanos de las Naciones Unidas. Folleto informativo $n^{\circ}$ 9. Oficina del Alto Comisionado, Nueva York.

Naciones Unidas (2016). Informe del relator especial sobre la extrema pobreza y los derechos humanos sobre su misión a Chile. Consejo de Derechos Humanos $32^{\circ}$ periodo de sesiones.

Rey, German (2002). "Cultura y desarrollo humano: unas relaciones que se trasladan”, Revista Digital de Cultura Pensar Iberoamérica. Website: http://www. campus-oei.org/pensariberoamerica/ric00a04.htm [03/03/2017].

Rodríguez, Simone y Domínguez, Carlos (2011). Sociedades plurales, multiculturalismo y derechos indígenas en América Latina. Política y Cultura (35), primavera, pp.:49-66.

Rubilar, Gabriela y Roldán, Andrés (2014). Áreas de desarrollo indígena: estudio de caso del ADI Puel Nahuelbuta como estrategia de las políticas públicas en el mundo mapuche. Universum, vol. 2, No 29, pp: 253-276.

Walsh, Catherine (2000). "Interculturalidad y la nueva lógica cultural de las políticas de Estado", en Vega y Román (eds.) Memoria Seminario Andino: Conflictos y Politicas Interculturales. Territorios y Educaciones. Cochabamba: CEIDIS. 
Walsh, Catherine (2006). "Interculturalidad y (de)colonialidad. Diferencia y nación de otro modo", en Desarrollo e interculturalidad, imaginario y diferencia: la nación en el mundo Andino, Quito: Académica. 